\title{
The Influence of Lavender Aroma Therapy on Decreasing Blood Pressure in Hypertension Patients
}

\author{
Agustina Boru Gultom $^{1}$, Surita Ginting ${ }^{2}$, Elni Lorensi Silalahi ${ }^{3}$ \\ Nursing Department, Health Polytechnic Ministry of Health, Medan, Indonesia
}

\begin{tabular}{l} 
Article Info \\
\hline Article history: \\
Received Sep 9, 2016 \\
Revised Nov 9, 2016 \\
Accepted Nov 23, 2016 \\
\hline
\end{tabular}

Keyword:

Aroma therapy

Blood pressure

Lavender

\begin{abstract}
The objective of this research was to determine the influence of lavender aromatherapy on decreasing blood pressure in hypertension patients. The research employed quantitative method with quasi experiment design. The samples were 32 patients either in the treatment group or in the nontreatment group. They were selected by consecutive sampling technique. The result of the research showed that the decrease in systolic and diastolic blood pressure of the treatment group was $9.7299 \mathrm{mmHg}$ and $4.3237 \mathrm{mmHg}$ while without treatment was $7.0461 \mathrm{mmHg}$ and $3.51152 \mathrm{mmHg}$. Paired t-test resulted the probability value of systolic blood pressure was a $(0.000)<0.05$, the probability of diastolic blood pressure was a $(0.000)<0.05$. It could be concluded that there was the influence of lavender aromatherapy on the decrease in systolic and diastolic blood pressure. Inhalation with lavender aromatherapy method can become one of the considerations in nursing intervention to decrease blood pressure in hypertension patients. It can be an alternative of therapy complement besides medication.
\end{abstract}

Copyright $\odot 2016$ Institute of Advanced Engineering and Science. All rights reserved.

\section{Corresponding Author:}

Surita Ginting,

Nursing Department, Health Polytechnic Ministry of Health, Medan,

North Sumatera, Indonesia.

Email: surita_ginting@yahoo.com

\section{INTRODUCTION}

Hypertension or raised blood pressure is estimated to have caused 9.4 million deaths and $7 \%$ of disease burden-as measured in DALYs-in 2010. Worldwide, detection, treatment and control of hypertension are inadequate, owing to weaknesses in health systems, particularly at the primary care level [1]. Anti-hypertensive drugs are associated with adverse side effects, although the majority of symptoms were mild, such as dizziness, headache, or rash. The older the patient, the more severe the side effects become, including arrhythmias or renal dysfunction [2]. Lavender is a heart sedative and can help to reduce palpitations and lower blood pressure [3].

Hypertension, an abnormal rise in blood pressure, occurs when the arterioles become constricted, reducing the ability of the blood to flow and making the heart work harder [2]. Globally, cardiovascular disease accounts for approximately 17 million deaths a year, nearly one third of the total. Of these, complications of hypertension account for 9.4 million deaths worldwide every year. Hypertension is responsible for at least $45 \%$ of deaths due to heart disease, and $51 \%$ of deaths due to stroke [4].

According to American Heart Association [5], there were about 77.9 million adults having high blood pressure in the United States. Of those who underwent blood pressure, 81.5 percent are aware they have it, 74.9 percent are under current treatment, 52.5 have it controlled, and 47.5 percent do not have it controlled. High blood pressure was listed on death certificates as the primary cause of death of 61,762 Americans in 2009 [5].

Medications carry inherent risk; therefore both pharmacological and non-pharmacological treatments are warranted. The pharmacological management of hypertension is directed at lowering or controlling blood pressure with the least amount of medication [6]. Not all patients diagnosed with 
hypertension require medication, but those at medium to high risk will need one or more of eight essential medicines to lower their cardiovascular risk (a thiazide diuretic, an angiotensin converting enzyme inhibitor, a long-acting calcium channel blocker, a beta blocker, metformin, insulin, a statin and aspirin) [4].

Anti-hypertension medicines are effective in decreasing morbidity and mortality in elderly people. However, the British National Health Care Center for Review and Dissemination at the University of New York (1999) revealed that all of the main classes of hypertension medicines are related to the additional sideeffect even though the majority of symptoms are moderate such as dizzy, headache, and rash, tiny red spots on the skin. In the old age, the side effect is more serious; it includes arrhythmia or kidney dysfunction [2]. Kaplan stresses that nondrug therapies may provide enough anti-hypertensive effect to lower blood pressure to a safe level without the need for antihypertensive drugs. Nondrug therapies consist of dietary modification (sodium, calcium, potassium, cholesterol), weight reduction, life-style habit changes (smoking, alcohol, physical activity), and behavior modification (e.g. biofeedback, progressive relaxation, cognitive restructuring and anger modulation) [6].

Aromatherapy can help as adjunctive relaxing therapy, and some essential oils are thought to help reduce borderline hypertension [2]. Some essential oils have affinities with certain organs or systems, and will have a special effect on that organ or system when at the point in its circulating journey. Whatever part of the essential oil is left after its therapeutic work in the body has been done, will be excreted by one path or another. It may be passed out of the body in urine or faeces, excreted through the skin as sweat or returned to the lungs to be exhaled with the breath [3].

Some types of aromatherapy which can be used to decrease hypertension are sage, rosemary, and lavender [2]. Tisserand (1988), Lavandula augustifolia (true Lavender), thought to reduce the effect of external emotional stimuli by increasing gamma-amino butyric acid (GABA), which in turn inhibits neurons in the amygdale, producing a sedative effect similar to that of diazepam. It is one of the most widely used and researched essential oils and its recognized as a relaxant [7]. Westwood (1991) states lavender helps balance the mind and emotions. On the other hand, it stimulates apnoeic reflex by closing larynx and causes parasympathetic general response by the decrease either in blood pressure or in heartbeat [2-3], [7].

Lavender aromatherapy can be used by inhalation method or smear it on skin while massaging it. However, inhalation is the simplest, the fastest, and also the oldest method [2]. The absorption of essential oils into the bloodstream via the respiratory system is slower and more diffusive than any other form of application, and essential oils will not build up high levels of concentration (as long as sensible proportion are used), due to the fact that the oils are constantly being removed from the bloodstream by one or more exit pathways [3].

The process of how lavender aromatherapy can help decrease blood pressure is as follows: the particles of essential oil which are easily evaporated under goes evaporation when it is contacted with air. Aroma particles of essential oil is dissolved in mucosa through the inside nasal cavity which has gotten stimulation from the receptor. The tied aromatic molecules are removed through cilia which are protruded from olfactorius receptor. This olfactory cell receptor has long nerve tissue which is called axon and an aroma electric chemistry message which is transmitted along the axon of receptor cell merges with olfactorius nerve. Olfactorius nerve tissue passes through a plate where ethmoid bone is stored in nasal roof and then reaches olfactorius bulbus where an aroma signal is chemically changed before it is sent out to the brain. As soon as the message reaches olfactorius bulbus, impulse of olfactorius cell passes into olfactory canal and directly to cerebral cortex where the aroma is perceived. Temporal lobus from the brain contains primary olfactorius area and is directly connected with limbic area/system [2-3]. Limbic system is a complete ring of brain structure in cerebral cortex. The main structures in limbic system are amygdala, septum, hippocampus, anterior thalamus, and hypothalamus. These structures are connected with a number of intricate pathways. Amygdala and hippocampus are the main regio in processing the aroma. Amygdala plays an important role in processing aroma and forms emotional memory; in this case, amygdala arranges emotional response. Limbic system interacts with cerebral cortex and gives the contribution by the relation between thinking and sensing, and has direct connection with parts of the brain which control heartbeat, blood pressure, respiration, level of stress, and hormonal content [7]. Even though essential oil inhalation is generally related to olfactorius, several molecules from inhaled particles will pass through lungs where the molecules will directly influence respiration and can be absorbed into the circulation system [7].

The research conducted by Sayorwan et al., on the effect of lavender oil inhalation on emotional states, autonomic nervous system, and brain electrical activity indicated that lavender oil could cause significant decrease in blood pressure, heartbeat, and skin temperature which indicated an autonomous system of reduction [8].

The research conducted by Myeong-Sook Ju et al, on the effect of aroma massage on home blood pressure, ambulatory blood pressure, and sleep quality in middle-aged women with hypertension indicated 
that lavender oil with marjoram, ylang-ylang, and neroli could cause significant decrease home SBP and immediate office BP before and after the intervention as wel as increasing sleep quality [9].

The preliminary survey done at the UPT Pelayanan Sosial Lanjut Usia (Technical Service Unit of Social Service for Elderly People), Binjai, reveals that there were 180 elderly people at the UPT and 40 of them suffered from hypertension. Based on the preliminary survey by interviews with 10 elderly people, it was found that all of them liked lavender aromatherapy. Based on the preliminary survey done at Posyandu Lanjut Usia Mekar 2, Puskesmas Pembantu Selayang, by providing treatment, measuring blood pressure pre and post intervention on elderly people inhaling lavender aromatherapy within 10 minutes for 5 elderly people, it was found that the mean disparity in post- and pre-systolic blood pressure was $18 \mathrm{mmHg}$ and the mean disparity in pre- and post-diastolic blood pressure was $8 \mathrm{mmHg}$. Based on the explanation above, the research problems could be formulated as whether there was the influence of lavender aromatherapy on the decrease in hypertension patients' blood pressure at the UPT Pelayanan Sosial Lanjut Usia, Binjai." The objective of the research was to analyze the influence of lavender aromatherapy on the decrease in blood pressure of hypertension patients at the UPT Pelayanan Sosial Lanjut Usia, Binjai.

The hypothesis of the research was that tere was the influence of lavender aromatherapy on the decrease in blood pressure of hypertension patients. This research is useful for UPT Pelayanan Sosal Lanjut Usia, Binjai, in which the result of this research is expected to be an input for increasing nursing care in hypertension patients by increasing blood pressure, for educational institutions this research could be used as information source in education and research development program, and for researcher as a support in applying science and experience in this research to carry out teaching process in the field of surgical medical nursing and gerontic care.

\section{RESEARCH METHOD}

The research used quantitative method with quasi experiment and subject equal design Subject equal design is a serial design in which all samples undergo activities and two periods in different time. The first period is intervention period in which the samples are given the intervention within two weeks (14 days). Then, it is alternated by the period of Washing out Period which is aimed to eliminate the effect of the first activity toward the next activity. The length of Washing out Period is three days. Then the second period is the control period in which the samples are not given intervention by using the similar subject within two weeks (14 days).

The research was conducted at the UPT Pelayanan Sosial Lanjut Usia, Binjai. The selection of the research location was based on the consideration that the elderly people were in the same location so that it made this research easier. The research was conducted from May until June, 2015. The population was all 40 elderly people who underwent hypertension at the UPT Pelayanan Sosial Lanjut Usia, Binjai, based on the preliminary survey. The samples were taken by using formulation sampling for numerical data in paired-group t-test. The samples were 32 elderly people who suffered from hypertension, taken by using consecutive sampling technique.

The sample criteria in this research were as follows: elderly people who underwent hypertension with the increase in blood pressure $\geq 140 / 90 \mathrm{mmHg}$, they had full awareness and did not undergo place, time, and human disorientation, they could communicate by using good Indonesian, and 6they were willing to become the respondents and followed the research procedure until the end.

The method of gathering the data was as follows: 1) During the process of gathering the data, the researchers explained the benefit of the research and the procedure of the research to the respondents-to-be to follow the research procedure and were willing to participate by signing the Informed Consent. 2) They agreed to follow the research procedure and fulfilled the criteria, filled out their bio-data which included their age and sex which had been prepared by the researchers. 3) In the first period, respondents were given pretest with sphygmomanometer of Nova brand and stethoscope of Litmann brand in order to measure their blood pressure which would be written in the observation sheets, and they were given lavender oil by using inhalation. By the time the blood pressure was measured, the respondents were asked to sit down comfortably, their right hands were open and put them on the flat tables and mercury manometer scale center was put parallel with the researchers' eyes. After their blood pressure was measured, the respondents were given 5 drops of lavender oil. Before that, they were told to exercise for taking deep breath (inhaling) in the count of 5, holding their breath in the count of 5, and exhaling in the count of 5. After they did what had been asked, they were given lavender oil in a piece of cotton which was given close to their noses (around $3 \mathrm{~cm}$ ) and asked to take their breath in 10 minutes. Post-test was then carried out by measuring their blood pressure, using sphygmomanometer, Riesta Nova brand, and stethoscope Litmann brand; the result was written on the observation sheet. This activity took two weeks (14 days). 4). Washing out Period (WOP) is the period of eliminating the effect of the previous intervention. It was done in 3 days; in this period there was no 
measurement of blood pressure. 5) In the second period, the respondents were given pre-test and pot-test with sphygmomanometer of Riester Nova brand and stethoscope of Litmann brand to measure blood pressure in which the result would be written in the observation sheets without giving lavender oil to be inhaled. The interval of measuring blood pressure between pre-test and post-test was 10 minutes. This activity took 2 weeks (14 days). The aspect of measuring blood pressure used ratio scale.

The data were analyzed by using paired t-test in order to assess the disparity between systolic blood pressure and diastolic blood pressure in pre and post intervention at the significance value of 5\% which was said that it was significant when $\mathrm{p}<0.05$

\section{RESULTS}

The research was concerned with "The Influence of Lavender Aromatherapy on the Decrease in Blood Pressure in Elderly People with Hypertension at the UPT Pelayanan Sosial Lanjut Usia, Binjai." It was conducted from May 18 until June 17, 2015. Intervention with lavender aromatherapy for the respondents was given in the research conducted from May 18 until May 31, 2015. Washing out Period was from June 1 until June 3, 2015, and then intervention without lavender aromatherapy for the respondents was done from June 4 until June 17, 2015. At the beginning, the samples were expected to be 40 respondents, but only 32 of them were willing to be involved in the research.

\subsection{Respondents' characteristics}

Respondents' characteristics in this research included age and sex (see Table 1). Table 1 shows the distribution of the respondents' characteristics. This table describes that the percentage age of 60-70 was similar to $>70$ and most of them were females $(53.1 \%)$.

Table 1. Distribution of Respondents' Characteristics

\begin{tabular}{lcc}
\hline \multicolumn{1}{r}{ Variable } & Frequency & Total $(\%)$ \\
\hline Age & & \\
$60-70$ & 16 & $50 \%$ \\
$>70$ & 16 & $50 \%$ \\
Sex & & \\
Male & 15 & $46.9 \%$ \\
Female & 17 & $53.1 \%$ \\
\hline
\end{tabular}

\subsection{Measuring blood pressure with lavender aromatherapy intervention}

Measurement took 14 days in pre and post intervention with lavender aromatherapy given to the respondents. Table 2 indicates that the mean value of respondents' systolic blood pressure in pre-lavender aromatherapy intervention was $165.592 \mathrm{mmHg}$ with the minimum value of $141.6 \mathrm{mmHg}$ and the maximum value of $211.9 \mathrm{mmHg}$. The mean value of respondents' diastolic blood pressure in pre-lavender aromatherapy intervention was $90.112 \mathrm{mmHg}$ with the minimum value of $73.6 \mathrm{mmHg}$ and the maximum value of $122.8 \mathrm{mmHg}$. Based on Table 2, it could also be seen that the respondents were given lavender aromatherapy intervention in 10 minutes, and then their blood pressure was measured in which their systolic blood pressure was $155.862 \mathrm{mmHg}$ with the minimum value of $134.9 \mathrm{mmHg}$ and the maximum value of $197.0 \mathrm{mmHg}$. The mean value of respondents' diastolic blood pressure in post non-lavender aromatherapy intervention was $85.788 \mathrm{mmHg}$ with the minimum value of $69.1 \mathrm{mmHg}$ and the maximum value of $128.6 \mathrm{mmHg}$.

Table 2. Description of the Mean Value of Respondents' Blood Pressure in Pre and Post Lavender Aromatherapy Intervention

\begin{tabular}{cccc}
\hline Variable & Mean & SD & Min-Max \\
\hline Mean systolic pre- intervention & 165.592 & 15.7490 & $141.6-211.9$ \\
Mean diastolic pre- intervention & 90.112 & 10.6017 & $73.6-122.8$ \\
Mean systolic post- intervention & 155.862 & 15.1352 & $134.9-197.0$ \\
Mean diastolic post-intervention & 85.788 & 11.1837 & $69.1-128.6$ \\
\hline
\end{tabular}

\subsection{Measuring blood pressure with non-lavender aromatherapy intervention}

Fourteen days after the intervention with lavender aromatherapy and intervention without lavender aromatherapy were given to the respondents in the first activity, in order to eliminate the effect of the first activity, respondents were given Washing out Period in three days. The next 14 days, their blood pressure

The Influence of Lavender Aroma Therapy on Decreasing Blood Pressure in .... (Agustina Boru Gultom) 
was observed once again without being given lavender aromatherapy intervention. After Washing out Period had passed, it was found that one respondent dropped out from the research program. Observation on respondents' blood pressure was continuously done twice, first (pre) and ten minutes later (post). The result can be seen in Table 3.

Table 3. Description of the Mean Value of Respondents' Blood Pressure in Pre and Post Non-Lavender Aromatherapy Intervention

\begin{tabular}{lccc}
\hline \multicolumn{1}{c}{ Variable } & Mean & SD & Min-Max \\
\hline Mean systolic pre-non-intervention & 162.281 & 14.9095 & $135.7-206.4$ \\
Mean diastolic pre-non- intervention & 86.774 & 6.0383 & $75.0-106.4$ \\
Mean systolic post-non- intervention & 155.235 & 13.5110 & $133.6-194.3$ \\
Mean diastolic post-non-intervention & 90.2857 & 6.12164 & $82.07-108.57$ \\
\hline
\end{tabular}

Table 3 indicated that the mean value of respondents' systolic blood pressure in pre non-lavender aromatherapy intervention was $162.282 \mathrm{mmHg}$ with the minimum value of $135.7 \mathrm{mmHg}$ and the maximum value of $206.4 \mathrm{mmHg}$. The mean value of respondents' diastolic blood pressure in pre non-lavender aromatherapy intervention was $86.774 \mathrm{mmHg}$ with the minimum value of $75.0 \mathrm{mmHg}$ and the maximum value of $106.4 \mathrm{mmHg}$. Based on Table 5.4, it was also seen that the mean value of respondents' systolic blood pressure in post non-lavender aromatherapy intervention was $155.235 \mathrm{mmHg}$ with the minimum value of $133.6 \mathrm{mmHg}$ and the maximum value of $194.3 \mathrm{mmHg}$. The mean value of respondents' diastolic blood pressure post non-lavender aromatherapy intervention was $90.2857 \mathrm{mmHg}$ with the minimum value of $82.07 \mathrm{mmHg}$ and the maximum value of $108.57 \mathrm{mmHg}$.

\subsection{The disparity of blood pressure in pre and post lavender aromatherapy intervention from blood pressure in pre and post non-lavender aromatherapy intervention}

Paired t-test had to be used to find out the mean disparity in respondents' blood pressure in pre and post intervention with lavender aromatherapy and in pre and post non-lavender aromatherapy intervention on condition that the data had to be distributed normally. By using Kolmogorov-Smirnov test, it was found that the disparity of data in the respondents' blood pressure in pre and post lavender aromatherapy was given in normal distribution was p-value $>0.05$ at the significance level of $95 \%$; therefore, it was appropriate to use paired t-test. The result of paired t-test is presented in Table 4.

Table 4. Disparity in Blood Pressure in Pre and Post Intervention with and in Pre and Post Non-intervention

\begin{tabular}{lccc}
\hline \multicolumn{1}{c}{ Pair } & Mean & Correlation & $P$ \\
\hline $\begin{array}{l}\text { Mean systolic pre-intervention -systolic } \\
\text { post-intervention }\end{array}$ & 9.7299 & 0.953 & 0.000 \\
$\begin{array}{l}\text { Mean diastolic pre- intervention -diastolic } \\
\text { post-intervention }\end{array}$ & 4.3237 & 0.957 & 0.000 \\
$\begin{array}{l}\text { Mean systolic pre-non-intervention -systolic } \\
\text { post-non-intervention }\end{array}$ & 7.0461 & 0.981 & 0.000 \\
$\begin{array}{l}\text { Mean diastolic pre- non-intervention- } \\
\text { diastolic post-non-intervention }\end{array}$ & -3.51152 & 0.892 & 0.000 \\
\hline
\end{tabular}

Table 4 informs that the mean disparity in systolic blood pressure in pre and post lavender aromatherapy intervention was $9.7299 \mathrm{mmHg}$ at the correlation value of 0.953 , and based on the result of paired t-test it was found that the probability value of systolic blood pressure was $\alpha(0.000)<0.05$, while the mean disparity in diastolic blood pressure in pre and post lavender aromatherapy intervention was 4.3237 $\mathrm{mmHg}$ at the correlation value of 0.975 , and based on the result of paired t-test it was found that the probability value of diastolic blood pressure was $\alpha(0.000)<0.05$. Based on Table 4 , it was found that the mean disparity value of systolic blood pressure in pre and post non-lavender aromatherapy intervention was $7.0461 \mathrm{mmHg}$ at the correlation value of 0.981 , and based on the result of paired t-test it was found that the probability value of systolic blood pressure was $\alpha(0.000)<0.05$, while the mean disparity value of diastolic blood pressure in pre and post non-lavender aromatherapy intervention was $-3.51152 \mathrm{mmHg}$ at the correlation value of 0.892 , and based on the result of paired t-test it was found that the probability value of diastolic blood pressure was $\alpha(0.000)<0.05$. 


\section{DISCUSSION}

The result of the research showed that the age of the respondents who suffered from hypertension was between 60 and 70 years old and 16 respondents were $>70$ years old. This study showed that there was no significant relation of hypertension with advancing in the age of the respondents who suffered from hypertension.

It was also found that there was no significant disparity in the sex of the respondents who suffered from hypertension. In males there were 15 respondents who suffered from hypertension while in females there were 17 respondents who suffered from hypertension. It was found that the percentage was higher in males than in females who suffered from blood pressure until they were 45 years old. From 45 to 54 years old and 55 to 64 years old, the percentage of males and females was similar, and after that the percentage was higher in females than in males in suffering from hypertension [5], [10].

The result of the research showed that the respondents' systolic blood pressure in pre lavender aromatherapy intervention was $165.592 \mathrm{mmHg}$ with the minimum mean value of $141.6 \mathrm{mmHg}$ and the maximum mean value of $211.9 \mathrm{mmHg}$. The increase in blood pressure can be measured as the consequence of age in the industrial society and hypertension is in high proportion in old-age population. The phenomenon of the increase in systolic blood pressure generally occurs in the elderly people at about 160-219 $\mathrm{mmHg}[11]$.

The result of the research showed that the mean value of the respondents' diastolic blood pressure in pre-lavender aromatherapy intervention was $90.112 \mathrm{mmHg}$ with the minimum mean value of $73.6 \mathrm{mmHg}$ and the maximum mean value of about $122.8 \mathrm{mmHg}$. It could be seen that the minimum mean value of diastolic blood pressure in pre-lavender aromatherapy intervention was a normal value because it was under $90 \mathrm{mmHg}$. However, if it was compared with the minimum mean value of systolic blood pressure in pre lavender aromatherapy intervention, it was $141.6 \mathrm{mmHg}$ so that systolic blood pressure could be categorized as the one which could be affected by hypertension. According to Lloyd-Jones et al., (1999), in the evaluation of blood pressure standard of 4.962 older respondents, it was found that $94 \%$ of them underwent the increase in systolic blood pressure, but only $33 \%$ of them underwent the increase in diastolic blood pressure [12].

It was also found that respondents were given lavender aromatherapy intervention in 10 minutes; then, the blood pressure was measured and it showed that the mean value of respondents' systolic blood pressure in post lavender aromatherapy intervention was $155.862 \mathrm{mmHg}$ with the minimum mean value of systolic blood pressure was $134.9 \mathrm{mmHg}$ and the maximum mean value was $197.0 \mathrm{mmHg}$ so that the mean disparity of systolic blood pressure in pre and post lavender aromatherapy intervention was $9.7299 \mathrm{mmHg}$. Meanwhile, the mean value of respondents' diastolic blood pressure in post lavender aromatherapy intervention was $85.788 \mathrm{mmHg}$ with the minimum mean value of diastolic blood pressure was $69.1 \mathrm{mmHg}$ and the maximum mean value was $128.6 \mathrm{mmHg}$ so that the mean disparity of diastolic blood pressure in pre and post lavender aromatherapy intervention was $4.3237 \mathrm{mmHg}$. This indicates that there is the decrease in systolic and diastolic blood pressure in post lavender aromatherapy intervention within 10 minutes. This is in accordance with the opinion which says that lavender aromatherapy can restrain motoric spontaneous activity and make mood more relaxed. Its effect on the autonomous system was that it can decrease anxiety and give sedative effect [7], [13]. This idea is supported by the research conducted by Jia-xiia about inhalation effect of different concentrations of lavender essential oil on blood pressure in hypertension patients which indicates that giving three types of different concentrations to respondents can decrease high blood pressure in elderly patients [14].

Hypothesis evidence in this research about mean disparity in systolic and diastolic blood pressure in pre and post lavender aromatherapy intervention, using paired t-test, showed that the probability value of systolic blood pressure was $\alpha(0.000)<0.05$ and the probability value of diastolic blood pressure was $\alpha(0.000)<0.05$. From the result of the research, it could be concluded that there was the influence of lavender aromatherapy on the decrease in systolic and diastolic blood pressure. This was in accordance with the opinion which said that lavender was an aromatherapy, one of the types of essential oil which could help decrease cardiac excitation and was effective in decreasing hypertension and palpitation [2], [15]. Lavender is a sedative or giving peace to the heart, decreasing palpitation or the sense of inconvenience in the chest, and decreasing blood pressure [3].

The result of the research was also supported by Sayorwan et al., about the research on the effect of lavender oil inhalation on emotional states, autonomic nervous system, and brain electrical activity which showed that lavender oil could cause significant decrease in blood pressure, heartbeats, and skin temperature which indicated the decrease in the autonomous system [8]. Besides that, the research conducted by Hur and Bae (2013) showed that there were the effects of aromatherapy essential oil inhalation on BP, PR, cortical serum in normotensive healthy adults after intensive exposure to white noise and arithmetic subtraction 
stressor by using lavender aromatherapy. Ylanglang also showed its significant effect on the decrease in systolic and diastolic blood pressure and doing inhalation within 10 minutes [16].

After the respondents were given lavender aromatherapy intervention within 14 days, they could get washing out period for three days in order to remove the effect of the first activity to prepare for another activity. Observation on respondents' blood pressure was continued for another 14 day period without being given lavender aromatherapy intervention. This observation was done twice: pre-observation and postobservation in ten minutes. The result showed that the mean value of respondents' systolic blood pressure in pre non-lavender aromatherapy intervention was $162.281 \mathrm{mmHg}$ with the minimum mean value of systolic blood pressure of $135.7 \mathrm{mmHg}$ and the maximum mean value of $206.4 \mathrm{mmHg}$. The mean disparity value of respondents' systolic blood pressure with pre and post non-lavender aromatherapy intervention was $7.046 \mathrm{mmHg}$. Meanwhile, the mean value of respondents' diastolic blood pressure in pre non-lavender aromatherapy intervention was $86.774 \mathrm{mmHg}$ with the minimum mean value of diastolic blood pressure of $75.0 \mathrm{mmHg}$ and the maximum mean value of $106.4 \mathrm{mmHg}$. The mean disparity value of respondents' diastolic blood pressure in pre and post non-lavender aromatherapy intervention was -3.51152 .

When the mean disparity of respondents' systolic blood pressure in pre and post intervention was compared with that in pre and post non-intervention, it revealed that both of them were similar in which both of them decreased. However, the amount of decrease of the mean disparity value of respondents' systolic blood pressure in pre and post intervention was higher than that in pre and post non-intervention. This indicated that lavender aromatherapy was effective in decreasing blood pressure because the group that was given lavender aromatherapy intervention had more significant decrease than that which did not get any lavender aromatherapy intervention. This was supported by the research conducted by Cho et al (2013) on effects a lavender, roman chamomile, and neroli oil blend aromatherapy on the anxiety, vital signs, and sleep quality of percutaneous coronary intervention patients in intensive care units. It was indicated by t-test $\mathrm{p}=0,011$, which showed that a lavender, roman chamomile, and neroli oil blend aromatherapy could decrease blood pressure patients coronary artery diseases in an intensive care [17].

In the group which was not given intervention the decrease in the disparity of systolic blood pressure in pre and post non-intervention also occurred even though it was not as high as the decrease in systolic blood pressure of the intervention group. This was possible because of the other factors such as dieting, physical activity, avoiding stress, and medicines. There are two methods in hypertension medication: pharmacological medication and non-pharmacological medication [6]. Pharmacological medication for hypertension is usually combined with some medicines such a thiazide diuretic, an angiotensin converting enzyme inhibitor, a long-acting calcium channel blocker, a beta blocker, metformin, insulin, a statin and aspirin) [4]. Non-pharmacological medication consist of dietary modification (sodium, calcium, potassium, cholesterol), weight reduction, life-style habit changes (smoking, alcohol, physical activity), and behavior modification (e.g, biofeedback, progressive relaxation, cognitive re-structuring and anger modulation) [6]. Pinto (2007) pointed out that blood pressure management for elderly people included medicines, changing in lifestyle which consisted of decreasing salt intake, and conducting physical exercise program [18].

The amount of decrease in systolic blood pressure in the group which was given lavender aromatherapy intervention was different from the amount of decrease in systolic blood pressure in the group which was not given lavender aromatherapy intervention $(7.0641 \mathrm{mmHg})$. This was supported by systematic review by Dickinson et al., 2006 on lifestyle interventions to decrease raised blood pressure : a systematic review of randomized controlled trials which pointed out that increased diet, aerobic exercises, and restricting alcohol, salt, and fish oil could decrease systolic blood pressure from $5.0 \mathrm{mmHg}$ (significance level of $95 \%$ : $3.1-7$ ) to $4.6 \mathrm{mmHg}$ (significance level of $95 \%$ : $2.0-7.1$ ) to $3.8 \mathrm{mmHg}$ (significance level of $95 \%$ : 1.4-6.1) to $3.6 \mathrm{mmHg}$ (significance level of $95 \%$ : $2.5-4.6$ ) to $2.3 \mathrm{mmHg}$ (significance level of $95 \%$ : $0.2-4.3$ ) with the similarity to the decrease in diastolic blood pressure [19].

However, when the mean disparity value of respondents' diastolic blood pressure in pre and post intervention is compared with the mean disparity value of respondents' diastolic blood pressure in pre and post non-intervention, it was found that they were not similar. The mean disparity value of respondents' diastolic blood pressure in pre and post intervention decreased while in pre and post non-intervention it increased which could be proved by its negative disparity even though it was still in the category of normally high in diastolic blood pressure. This was probably because some of the respondents underwent isolated systolic hypertension. Isolated systolic hypertension is defined as systolic blood pressure which was $\geq 140$ $\mathrm{mmHg}$ and diastolic blood pressure which was $<90 \mathrm{mmHg}$. This type of hypertension is hypertension which often occurs in elderly people and its prevalence increases, along with the increase in age in which two of the three persons who are more than 60 years old and three of the four person who are more than 75 years old suffered from isolated systolic blood pressure. The change in lifestyle is an initial effort to overcome and do medication in order to maintain blood pressure below 140/90 $\mathrm{mmHg}$ [20]. 
Lavender aromatherapy which was given to respondents in this research had significant effect so that lavender aromatherapy can be used as one of the nursing interventions to decrease blood pressure in hypertension patients. Basch et al., (2003) pointed out that aromatherapy could be given intermittently and, if necessary, once a day [21].

Controlling blood pressure needs patient's strong willingness but with general approach, easy to be used, and economical. Lavender aromatherapy can be considered as one of the nursing interventions at the UPT Pelayanan Sosial Lanjut Usia, Binjai, which can be used to decrease hypertension patients' blood pressure as a supplementary alternative therapy besides the usual medication.

There were some limitations in this research. There were related to minimizing confounding factors which would influence respondents in decreasing blood pressure in which some of the respondents took antihypertension medicines during the process of the research, the difference in salt and animal fat intake in food because respondents probably could get food with high salt and animal fat intake from the outside of the UPT, regular and different exercises of the respondents, and each respondent had his own way to avoid stress. Besides that, the limitations of this research were also related to the research design in which the research used quasi experimental design for the same subjects, but random technique on the subjects or respondents had not done yet.

\section{CONCLUSION}

The result of the research, using paired t-test, showed that probability value of the mean disparity value of systolic blood pressure in pre (in the first measurement) and post (the following 10 minutes) non-lavender aromatherapy intervention was $\alpha(0.000)<0.05$. This indicated that there was the mean disparity value of systolic blood pressure in pre (in the first measurement) and post (the following 10 minutes) non-lavender aromatherapy intervention. The result of the research also showed that by using paired t-test, the probability value of the mean disparity of diastolic blood pressure in pre (in the first measurement) and post (the following 10 minutes) non-lavender aromatherapy intervention was $\alpha(0.000)<0.05$. This indicated that there was the mean disparity value of diastolic blood pressure in pre (in the first measurement) and post (the following 10 minutes) non-lavender aromatherapy intervention. Based on the researchers' observation during the studying, the factors of dieting variation, physical activities, avoiding different stresses, and some respondents used anti-hypertension medicines had caused the decrease in blood pressure in non-intervention group. From this result, it was found that besides lavender aromatherapy, there were also some other alternatives to decrease blood pressure. The other alternatives which can often be done by elderly people is the change in lifestyle like reducing salt and animal fat intake in food, regular exercises, avoiding stress, and taking medicines. However, it has to be studied specifically to find out its effectiveness.

\section{ACKNOWLEDGEMENTS}

We thank Poltekkes institution who gave financial support for this study and we also thank the nurses who were active to help the researchers to provide hypertension patients at the UPT Pelayanan Sosial Lanjut Usia, Binjai. This research was supported by Health Polytechnic Ministry of Health, Medan, North Sumatera, Indonesia, Indonesia. Our special gratitude is for Dr. dr. Arlinda Sari W., M.Kes.from the Medical School, University of Sumatera Utara, Indonesia, who has been the reviewer of this research.

\section{REFERENCES}

[1] World Health Organization, "Global Status Report On non-communicable diseases," Geneva, Switzerland, pp. xv, 67,2014

[2] Buckle J., "Clinical Aromatherapy. Essential Oil in Practice," Second Edition, Philadelphia, Elsevier Science, pp. 29-32, 247-250, 2003

[3] McGuinness H., "Aromatherapy. Therapy Basics," Second Edition, London, Hodder Arnold, pp. 123, 2007.

[4] Wolrd Health Organization, "A global brief of HYPERTENSION. Silent killer, global public health crisis," Geneva, Switzerland, pp. 9, 2013.

[5] American Heart Association, "High Blood Pressure. Statistical Fact Sheet," accesses on October 22, 2014.

[6] Beare P. G. and Myers J. L., "Principles and Practice of Adult Health Nursing," St.Louis, CV. Mosby Company, vol. 1, pp. 713, 1990.

[7] Snyder M. and Lindquist R., "Complementary of Alternative Therapies in Nursing," sixth edition, New York, Springer Publishing Company, pp. 404-409.

[8] Sayorwan W., et al., "The Effects of Lavender Oil Inhalation on Emotional States, Autonomic Nervous System, and Brain Electrical Activity," J Med Assoc Thai, vol/issue: 95(4), pp. 598-605, 2012. 
[9] Ju M. S., et al., "Effect of Aroma Massage on Home Blood Pressure, Ambulatory Blood Pressure, and Sleep Quality in Middle-Aged Women with Hypertension," Evidence-Based Complementary and Alternative Medicine, 2013.

[10] Kearney P. M., et al., "Global Burden of Hypertension: Analysis of Worldwide Data," New Orleans, Lancet, vol. 365, pp. 217-223, 2005.

[11] Pinto E., "Blood Pressure and Aging," Postgrad Med J., vol/issue: 83(976), pp. 109-114, 2007.

[12] Tin L. L., et al., "Commentary Systolic vs Diastolic Blood Pressure and the Burden of Hypertension," Journal of Human Hypertension, vol. 16, pp. 147-150, 2002.

[13] Frisman W. H., et al., "Complementary and Integrative Therapies for Cardiovascular Disease," St Louis, Mosby Inc.

[14] J. Xia L., et al., "Inhalation Effect od Different Concentrations of Lavender Essential Oil in Blood Pressure in Hypertensive Patients," Anhui Medical and Pharmaceutical Journal, vol. 11, 2011.

[15] Battaglia S., "The Complete Guide to Aromatherapy," The International Centre of Holistic Aromatherapy, Brisbane, Australia, 2003.

[16] M. H. Hur and I. Bae, "The effects of aromatherapy essential oil inhalation on BP, PR, serum cortisol in normotensive healthy adults after intensive exposure to white noise and arithmetic subtraction stressor," International Conference on Nursing \& Emergency Medicine, Las Vegas, Omics Group Conferences, 2013.

[17] Cho M. Y., et al., "Effects of Aromatherapy on the Anxiety, Vital Signs, and Sleep Quality of Percutaneous Coronary Intervention Patients in Intensive Care Units," Evidenced-Based Complementary and Alternative Medicine, Korea, 2013.

[18] Pinto E., "Blood Pressure and Ageing," Postgraduate Medical Journal, vol/issue: 83(976), pp. 109- 114, 2007.

[19] H. O. Dickinson, et al., "Lifestyle interventions to reduce raised blood pressure: a systematic review of randomized controlled trials," Journal of Hypertension, Lippincott Williams \& Wilkins Inc, vol/issue: 24(2), pp. 215-233, 2006.

[20] J. Basile, "Hypertension in the Elderly: A Review of the Importance of Systolic Blood Pressure Elevation," Ralph H.Johnson VA Medical Center, Medical University of South Carolina, Charleston, 2002.

[21] Basch E., et al., "Monograph from Natural Standard. Lavender (Lavandula angustifolia Miller)," Journal of Herbal Pharmacotherapy Natural Standard, vol/issue: 4(2), pp. 61-72, 2003. 